\title{
plaque vulnerability
}

\section{Rizou A. ${ }^{1}$, Nasiri-Ansari N. ${ }^{1}$, Splioti E. ${ }^{1}$, Lianidou E. ${ }^{2}$, Moutsatsou P. ${ }^{1}$, A. Papavasileiou A. ${ }^{1}$, Kassi E.. ${ }^{1}$}

1. Department of Biological Chemistry, Medical School, National and Kapodistrian University of Athens, 11527 Athens, Greece.

2. Laboratory of Analytical Chemistry, Department of Chemistry, 15771, University of Athens, Greece

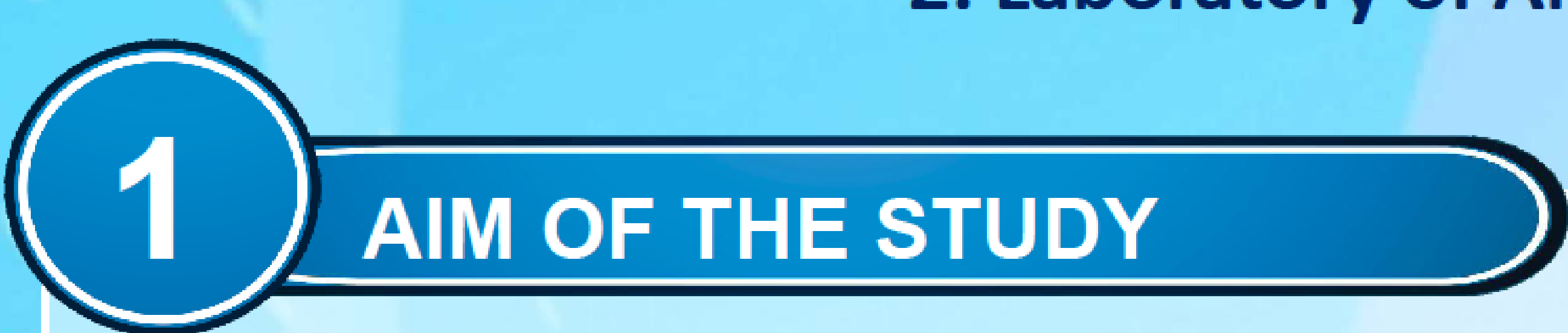

Although the protective effects of $1,25(\mathrm{OH})_{2} \mathrm{D}_{3}$ (Vit D) on the early stages of atheromatosis process have been investigated, data on its influence on factors implicated in plaque vulnerability are limited. Among the key vessel wall component in the later stages of atherogenic process is endothelium. During the stages of plaque ruptre and/or erosion metalloproteinases MMP-2, MMP-9, their inhibitors TIMP-1,TIMP-2, the RANKL-RANK-OPG system and MCP-1 which all expressed by endothelial cells, play a critical role. Herein, we aimed to investigate the effect of vitamin $D$ on the expression of the above factors on endothelial cells.

\section{MATERIALS AND METHODS}

$>$ Human aortic endothelial cells (HAECs) were incubated with VitD for $24,48,72$ hours at a concentration range $10^{-8}$ $-10^{-11}$ in the absence of TNF- $\alpha$ or with Vit D for 24 hours in the presence of TNF- $\alpha$ at concentration $10 \mathrm{ng} / \mathrm{ml}$ for the last 6 hours.

$>$ Real Time-PCR was used to quantitatively detect gene expression of MMP-2, MMP-9, TIMP-1, TIMP-2, OPG, RANKL, RANK and MCP-1.

> Gelatin zymography was used to detect MMP-2, MMP-9 activities in culture supernatants.

$>$ OPG protein levels were also evaluated by western blot. > Our results are expresed as mean SD. Two-tailed Students's test was used for our statistical analysis and $p$ value $<0.05$ was considered significant.

\section{Results}

* VitD did not significantly change the expression of MMP-9, MMP-2, TIMP-1 and TIMP-2 at mRNA level at various concentrations and incubation time-courses, however, decreased the expression of MCP-1 dose-dependently.

* The expression of OPG at mRNA was significantly increased in the presence of TNF-a and this effect became more pronounced when cells were preincubated with Vit $D$ at concentration $10^{-9} \mathrm{M}$. However, our results were not confirmed at protein level. Interestingly, incubation with p38 inhibitor, totally abolished the effect of Vit D on the mRNA OPG expression, indicating that this MAPK pathway is implicated in the regulation of $O P G$ expression by Vit $D$.

* When cells activated with TNF-a, preincubation with Vit D resulted in a significant decrease in MMP-9 expression at $10^{-10}$ and $10^{-11} \mathrm{M}$ and increase in TIMP-2 expression while it didn't affect the expression of MMP-2 and TIMP-1.

* Gelatin zymography revealed that Vit D decrease the active MMP-2 dosedependently with the effects being more pronounced at the lower concentrations.

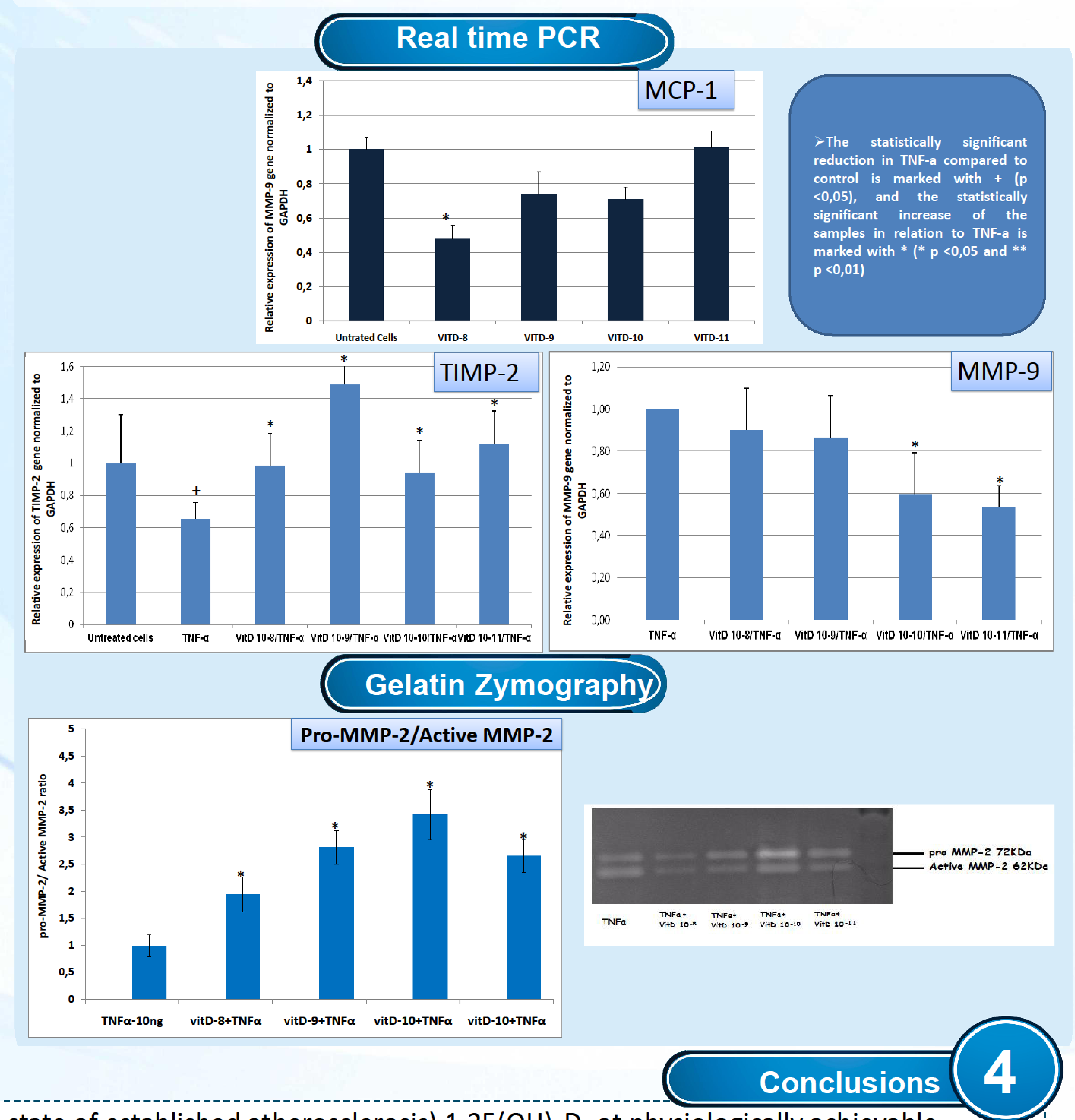

Conclusions

In the presence of TNFa (resembling the low grade inflammation state of established atherosclerosis) $1,25(\mathrm{OH})_{2} \mathrm{D}_{3}$ at physiologically achievable concentrations reduces the expression of MMP-9 and induces the expression of TIMP-2 at mRNA level implying a possible protective role in the later stages of atheromatosis, such as plaque vulnerability. Further studies are needed to elucidate the underlying mechanisms.

Kassi E, Adamopoulos C, Basdra EK, Papavassiliou AG. Role of vitamin D in atherosclerosis. Circulation 128,:2517-31 (2013). Virmani, R., Burke, A.P., Farb, A. \& Kolodgie, F.D. Pathology of the vulnerable plaque. J Am Coll Cardiol 47, C13-8 (2006).

Nagase, H., Visse, R. \& Murphy, G. Structure and function of matrix metalloproteinases and TIMPs. Cardiovasc Res 69, 562-73 (2006).
Nuclear receptors and Signal transduction

Naries Nasiri-Ansari

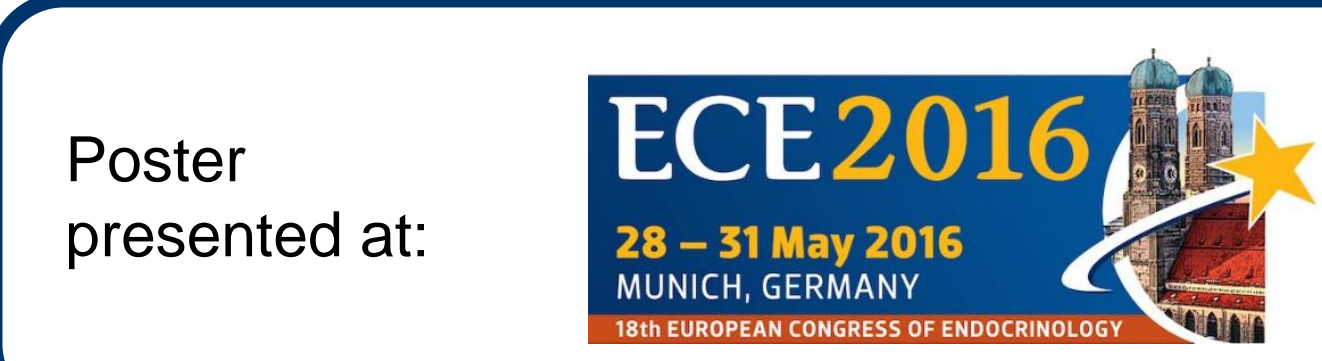

presented at

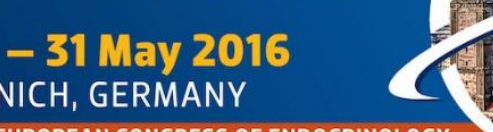

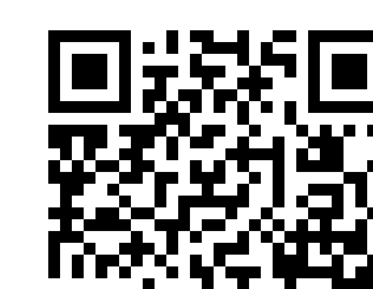

Pogter PostersionOnlicom 